mild type of fever then available and to be properly nursed through the different stages so that a rapid and complete convalescence may be insured. Some such scheme as the foregoing is, I consider, well worthy of the attention of sanitarians, since the control of the infantile fevers is, in my opinion, the key to the capture of one of the most important strongholds of consumption and will open the way to the undoubtedly approaching triumphal achievement of sanitary science, "the clearing away of consumption from the country." I am, Sirs, yours faithfully,

Lampeter, Nov. 5th, 1902 .

E. Clunegras Davies, M. D. Durn.

\section{NOTE ON THE DISCOVERY OF THE HUMAN TRYPANOSOME.}

To the Editors of THE LANCET.

SIRs,-Being responsible for the reference to trypanosoma which appeared in the Journal of Tropical Medicine of Nov. 1st, I feel that it is my duty to answer the very formal protest advanced against it in THE LANCET of Nov. 22nd, p. 1426, by Dr. Rubert Boyce, Major Ronald Ross, and Dr. C. S. Sherrington The protest of these gentlemen has surprised me in the extreme and $I$ am bound to say that even now I am unable to grasp the real motive which prompted their letter. Anyhow, I will suppose that they considered my communication an encroachment on their rights of priority, similar to that which they unfortanately made soon after Dr. Low's demonstration at the London School of Tropical Medicine, that the larval filaria Bancrofti, having reached a certain stage of development in the thoracic muscles of culex fatigans, migrates to the insect's trophi to be subsequently inoculated into a fresh human host. Had my communication been so devised, it would not yet have been a parallel case, because I sent it to a well-informed medical journal, whilst their notification appeared in the first instance in the lay press.

Anyone who will read my communication with an unbiased mind will, I am sure, be unable to see adequate reason for their protest. I did not attribute the discovery of the presence of trypanosoma in man either to Dr. P. Manson or to Dr. C. W. Daniels. I simply stated that Dr. Manson, having had the opportunity of examining Mr. R. M. Forde's patient in Liverpool was able to diagnose a second case which was subsequently studied at the London School of Tropical Medicine, and that Dr. Daniels had found, and of course recognised, the trypanosome just as Dr. Dutton had recognised the nature of the parasite found by Mr. Forde in his case. Further, I added that the presence of trypanosomes in a second case presenting the same striking and grave symptoms observed in Mr. Forde's patient showed that the presence of trypanosomes could no longer be regarded as a merể curiosity like many erratic parasites occasionally found in man, but must be looked upon henceforth in certain reginns as an important pathologicai factor.

I did not sign my hasty communication because its object was not that of advertising my name and I stated that an accurate account of the case would be published very shortly by those who were investigating it. I did not mention Dr. J. E. Dutton because it did not occur to me that he had anything whatever to do with the case I was reporting, and even now I utterly fail to see why I should have mentioned his name. In other publications on filaria, \&c., I have at opportune times mentioned Dr. Dutton's excellent work. In this instance I was not writing in praise of the Liverpool School that has been done lately to a large extent. I was merely mentioning an interesting case of trypanosoma infection.

Having explained the reason of my anonymous communication I must now myself protest against the very gratuitous accusation brought by Dr. Boyce, Major Ross, and Dr. Sherrington by saying: "We believe that such statements are calculated to distort the history of the discovery and should therefore like to have an opportunity for correcting them promptly in your pages." These gentlemen virtually accuse me of having attributed the discovery of the presence of trypanosoma in man to Dr. Manson and Dr. Daniels-a statement which I did not make nor ever dreamt of making. But what is still more surprising is that while they accuse me of distorting the history of this discovery they ascribe the honour of having made it to "an old student and assistant" of their laboratory. I am sorry that Major Ross, who has so strongly resented Professor Grassi's encroachments upon his work, should now set aside information of which he is evidently aware for the purpose of claiming for his own school the discovery of trypanosoma in man.

Major Ross and his colleagues, after having stated that "Dr. Dutton was the first clearly to observe and to signal the existence of trypanosomes in human blood, and the first to give accurate descriptions of the new organism," add, without mentioning dates and in the most unfair manner, that " Barron and Nepvew have also claimed to have found flagellates in human blood, but as will be seen from their writings, their desorptions are so inadequate as to fail to convince us of the accuracy or even the nature of their observations." (The italics are mine.) To disprove these erroneous statements $I$ can do no better than quote verbatim Dr. G. Nepvew's very clear account of his discovery of trypanosomes in man which, be it noted, he made between 1890 and 1898 , and published in the Comptes Rendus des Séances de la Société de Brologie of Dec. 24th, 1898, many years before Dr. Dutton's publication. Dr. Nepvew writes as follows :-

So far trvpanosomes have been found only in the blood of animals; in India they have been found in the blood of the rat (Lewis), the horse (surra epidemics), the dog, and the domesticated elephant. In Africa they have been discovered in the disease caused by the tsetse fly and in Europe in the blood of the rat, the rabbit, various birds, and the frog. No one seems to have found them yet in man; however, Laveran states that Barron seems to have found certain flagellated protozoa of an undetermined genus in the blood of an anæmic roman. In 1890, in consequence of researches made in Algeria on the malaria parasite, I found in the blood of a patient, besides Laverania, a flagellate which was rather common. because I could count about three in each preparation of 18 square millimetres. At about that time (see Nepvew. Eududes sur les Parasites du Sang chez les Paludiques, 21, 1891, in Bulletins et Mémoires de la Société de Biologie) I already pubthen that I might be able to complete my first observations by a more then that I might be able to complete my first observations by a more detailed stury, but after that only very rarely have I been able to find
that parasite. I have therefore decided to publish the following facts that parasite. I have therefore decided to publish the following facts in the hope of drawing the attention of such naturalists and physicians who will have the opportunity of completing these researches. This trypanosoma presents all the characters of the genus : general shape a homogeneous colourless membrane, one border of which is thinner, hyalin, and presents characteristic undulating movements. This anteriorly and the undulations of which follow in rapid succession. Thus it presents itself in Khill (quotidian fever), in Cabane (pernicious comatose fever). In a third patient, Ginestet, I have found certain organisms which I thought I might compare to those described under the name of trypanomonas, a form which is probably only an evolution stage of the trypanosoma. In this patient the organismos were pro-
vided with two flagella at one of their extremities. Labbé has described such a trypanomonas.

In over 200 patients, mostly malarial, of which I have examined the blood, I have only found these various forms in six-three of them were suffering from quotidian fever (Khill, Langevelle, Bichielli) one a double tertian (Hendrick), two the pernicious comatose fever (Cabane and Ginestet); the seventb observation was on Dr. X- who was apparently in good health. In "none of these patients have I been able to observe any symptoms characteristic of this special parasitic invasion. They were almost every one of them suffering from the effects of Laverania which prevailed on everybody and everywhere in its various forms. This seems therefore purely
cidence which has seemed to me worthy of notice.

In conclusion, trypanosoma must be classed amongst the parasites In conclusion, trypanosoma must be classed amongst the parasites
of human blood. I am unahle at present to give a more complete of human blood. I am unahle at present to give a more complete abstain from giving it a special name. It is better to establish first abstain from giving if a special name. It is better to establish first of man and the congeneric parasites of animals, and also to complete of man and the congenelic parasites of animals,
the observations on its morphology and life-history."

The above quotation speaks for itself and I will only add that there can be no question about Dr. Nepvew's bona fides. The two-flagellated organism he mentions in his paper is so peculiar a feature that it is not likely to be imagined. That it is a feature of the trypanosoma of man I can attest, because Dr. Daniels found it in the blood of our patient. It is to be regretted that the representatives of the Liverpool School of Tropical Medicine, in their praiseworthy endeavour to make a new discovery, should have again overlooked previous work.

I am, Sirs, yours faithfully,

Louis W. SAMBoN, M.D. Naples,

Nov. 27th, 1902

Lecturer at the London School of Tropical Medicine.

\section{THE AMBULANCE SERVICE OF LONDON.}

\section{To the Editors of THE LANCET.}

SIRs,-Dr. A. S. Morton has called attention to one of the many matters in which the metropolis of the Empire is far behind most other important towns--namely, the want of an ambulance service for accidents and non-infectious diseases. I have many years ago called attention, both locally and in medical papers, to this want. The police supply hand ambulances for accidents in the street but they are not allowed to be used for people going from a private 
house. Lady Strangford, I believe it was, presented the police with the ambulance to which I think Dr. Morton refers in uncomplimentary terms, many years ago. It is now, of course, quite out of date. The St. Juhn Ambulance Association has met the want for the wealthy but for the general public in London there is practically no ambulance service. I am glad to say, however, that for Woolwich I have at last succeeded this year in obtaining an ambulance by means of public subscriptions. £90 were raised in this way and an excellent horse ambulance was purchased. This is vested in trustees and is lent to a local cab proprietor who keeps it and lends it out for use whenever required at the statutory cab fares, so that anybody requiring removal to hospital can obtain now a well-equipped ambulance at the same price and with the same ease as an ordinary cab. I would suggest to Dr. Morton that he should try to supply Hammersmith with an ambulance in the same way and shall be glad to give him further particulars of my experience on the matter in Woolwich if he desires it.

I am, Sirs, yours faithfully, SIUNEY DAVIES,

Woolwich, Dec. 2nd, 1902. Medical Officer of Health of Woolwich.

*** We believe that the whole question of ambulances in London will shortly be brought before the London County Council in a report made to the Council by Sir Wrilliam Collins.-ED. L.

\section{THE ANATOMY OF GLENARD'S DISEASE.}

To the Editors of THE LANCHT.

SIRS, -I have read with much interest your editorial annotation on the subject of the Anatomy of Glénard's Disease. ${ }^{\text {I }}$ I have not had an opportunity of perusing Dr. Arthur Keith's lecture which forms the subject of its comment. But whether the original mistake is due to Dr. Keith or to his commentator the annotation in THE LANCET now before me gives a decidedly erroneous view of some of the most important items in the mechanism of inspiration. In dealing with the action of the diaphragm we are told that: "He proceeds to correct some current and erroneous ideas as to the action of this muscle, and shows that it will enlarge the thoracic cavity mainly by lengthening it, by a depression of the heart and abdominal viscera when the muscles of the belly wall are slack, but by increasing in a proportionately greater measure the width and depth of the chest by the elevation of the lower ribs when the belly wall is resistant either by reanon of its good muscular development or from the artificial support of corsets." Now I will take the liberty of pointing out to your readers that the action of the diaphragm has long been understood by skilled anatomists much better than it seems to be by the writer of the sentence here quoted. Fixed as it is by its more stable (circumferential) attach ments to the xiphoid cartilage in front, to the upper three or four lumbar vertebra behind, and to the lower six (sometimes one more or less) ribs on either side, its muscular fibres converge to the central " cordiform" tendon, to a con. siderable portion of whose upper surface the pericardium is firmly adherent. The intermediate muscular fibres form curves-in the quiescent state-strongly convex upwards towards the thoracic cavity. The necessary result of this arrangement is that the contraction of the muscle as a whole converts the individual curves of its fibres into approximately straight lines. As a necessary consequence there is increased depth of the circumferential regions of the thorax. But the central tendon is only very slightly depressed; there is little change in the position of the heart or of the other contents of the "middle mediastinum." The simultaneous contraction of all the intercostal muscles in the act of inspiration raises and rotates the ribs, thereby widening the chest and, by throwing forwards the sternum, increasing its antero-posterior depth. But the four lower ribs are, at the same time, subjected to a peculiar in. fluence which would appear to have been entirely overlooked by your commentator. A very interesting and important muscle, the serratus posticus inferior, used to be described by the older physiologists as a "muscle of expiration"-and very wrongly. Arising from the last two dorsal and first two lumbar vertebræ, this muscle is inserted into the four lower ribs-outside the vertical line of their "angles." Its contraction, necessarily, draw's these ribs downwards and backwards. By acting simultaneously with the diaphragm and intercostal muscles, it has the effect of widening the basal section of the thorax, where most expansion is attainable. Whenever the movements of the lower ribs are trammelled by the contraction of the aboiominal muscles the necessary result is deficient expansion of the thoracic cavity. And when the widening of the loose segment of the thorax is limited, as it necessarily always is, by the use of tight corsets the result is very similar. Here lies the real evil of the $u-e$ of corsets so far as the function of respiration is concerned. But nature has, I must observe, rather liberally provided for difficulties of respiration in this region in case of the female section of the population. Thoracic expansion with them is mostly of the "superior thoracic" type ; and accordingly they are found in practice much more tolerant of constriction in this region than the enemies of corsets usually assume them to be. I have known some " wasp-waisted" ladies who could run, walk-aye, and even talk - faster than most of their female, or any of their male, rivals in these departments of physical exertion.

I am, Sirs, yours faithfully,

Dublin, Nov. 19th, 1902.

JoHN KNOTT, M.D. Dub.

** Dr. Knott is criticising a paper which he has not read. His remarks as to the action of the diaphragm are mostly academically correct, but had he read the paper he would have gathered that several of his premisses are probably incorrect, particularly that which assumes the relative immobility of the central tendon. As to the assertion that the lower ribs are drawn downwards and backwards by the simultaneous contraction of the diaphragm, intercostals, and serratus posticus inferior, it is sufficient to remark that clinicians who have opportunities of watching the isolated actions of muscles in disease are all agreed that the diaphragm eievates the lower ribs.--ED. L.

\section{SHOULD PNEUMONIA BE CLASSIFIED AMONG THE SPECIFIC INFECTIVE DISEASES ?}

To the Editors of THE LANCET.

SIRS, - At the present time there is an increasing tendency to separate pneumonia from the diseases of the lung and to classify it among the specific infective diseases. This has been done in some of the recent text-books of medicine and presumably it will be discussed by the nomenclature committee of the Royal College of Physicians of London. The matter is one of great importance, not only with regard to pneumonia, but also with regard to the nomenclature of diseases generally. Since a disease is not a definite entity but is a state involving the idea of motion we cannot classify diseases in the same way as we can classify definite objeets. We can only classify them according to the factors concerned in their causation or according to the effects produced by them. These two methods of classitication are both necessary and neither can replace the other. The definition of a disease depends on its classification and the significance of the name depends on the definition. The name, therefore, of a disease connotes either a definite causal factor, or an effect, whether the effect be an anatomical or a functional change or a symptom. In the case of the specific infective diseases the name connotes a specific extrinsic causal factor. Although we do not know the causal factors concerned in the production of many of these diseases, yet from the fact that they breed true and from other evidence there can be no doubt that specific agents are concerned in their causation. The term "syphilis," for instance, connotes a specific but unknown causal factor and does not connote any definite effect. Again, the term "tuberculosis" used to connote a definite effect-namely, the presence of tubercles in the organs; now, however, the term connotes a specific causal agentthe bacillus-whether or not tubercles are present in the organs, and it therefore excludes all cases in which the tubercles are present but which are not due to the specific baeillus. This alteration in the connotation has led to a confusion in the nomenclature with the result that we have had introduced the unsatisfactory term "pseudotuberculosis."

Now the term "pneumonia" connotes a certain effectnamely, a certain condition of the lung, and this condition is 